\title{
On the preparation and characterization of superparamagnetic nanoparticles with Gelidium robustum agar coating for biomedical applications
}

\author{
DIANELA DÍAZ-BLEIS ${ }^{1}$, JUAN JOSÉ ALVARADO-GIL ${ }^{2}$, ARTURO I MARTÍNEZ ${ }^{3}$, \\ YOLANDA GÓMEZ-Y-GÓMEZ ${ }^{4}$ and YOLANDA FREILE-PELEGRÍN ${ }^{1, *}$ \\ ${ }^{1}$ Marine Resources Department, CINVESTAV-Mérida, Antigua Carretera a Progreso Km. 6, A.P. 97310 Mérida, Yucatán, \\ Mexico \\ ${ }^{2}$ Applied Physics Department, CINVESTAV-Mérida, Antigua Carretera a Progreso Km. 6, A.P. 97310 Mérida, Yucatán, \\ Mexico \\ ${ }^{3}$ CINVESTAV-Saltillo, Av. Industria Metalúrgica 1062, Parque Industrial Ramos Arizpe, 25900 Coahuila, Mexico \\ ${ }^{4}$ Pharmacology Laboratory, Instituto Politécnico Nacional, Unidad Profesional Interdisciplinaria de Biotecnología, Av. \\ Acueducto s/n Barrio La Laguna, Ticomán Del. Gustavo A. Madero, Mexico, Mexico \\ *Author for correspondence (yolanda.freile@ cinvestav.mx)
}

MS received 18 February 2017; accepted 13 June 2017; published online 23 March 2018

\begin{abstract}
Superparamagnetic nanoparticles coated with natural polysaccharides are of great interest for biomedical applications due to their fast response to an external and high-frequency electromagnetic field and their biocompatibility. One of the greatest challenges in the development of these nanoparticles is related to the specific characteristics and properties of the polysaccharide used, which could guarantee the development of specific sizes, crystalline structure, magnetic response and its reproducibility. In this study, we present the preparation of magnetite $\left(\mathrm{Fe}_{3} \mathrm{O}_{4}\right)$ and cobalt ferrite $\left(\mathrm{CoFe}_{2} \mathrm{O}_{4}\right)$ nanoparticles by the co-precipitation method in aqueous solutions at different concentrations $(1,2,3,4$ and $5 \%)$ of a very well-characterized agar obtained from the red marine algae Gelidium robustum. It is shown that under the same experimental conditions and using the adequate precursors, coated high-crystallinity magnetite nanoparticles are obtained. In contrast, for cobalt ferrite, our results indicated the formation of coated low-crystallinity $\mathrm{CoFe}_{2} \mathrm{O}_{4}$ particles. Superparamagnetic nanoparticles (with crystal grain size $<8 \mathrm{~nm}$ ) of $\mathrm{Fe}_{3} \mathrm{O}_{4}$ agar coated at $\geq 3 \%$ agar showed high-saturation magnetization and high degree of biocompatibility and can be considered as promising candidates for biomedical applications.
\end{abstract}

Keywords. Agar; superparamagnetic nanoparticles; magnetite; cobalt ferrite.

\section{Introduction}

During recent years, remarkable progress was made by synthesizing biocompatible and functionalized magnetic nanoparticles (MNPs) for use in biomedical applications such as drug delivery, magnetic resonance imaging and hyperthermia treatments. Materials used for magnetic biomedical applications should be superparamagnetic, non-toxic and biocompatible. These superparamagnetic materials are of interest because they do not retain any magnetism after removal of the magnetic field; this fact implies that non- or low-coercive forces exist, preventing magnetic dipolar interactions between particles and, eventually, their aggregation [1]. Superparamagnetic iron oxide nanoparticles (SPIONs) such as magnetite $\left(\mathrm{Fe}_{3} \mathrm{O}_{4}\right)$ and ferrites $\left(\mathrm{MFe}_{2} \mathrm{O}_{4}\right.$, where $\mathrm{M}$ is a divalent metal such as $\mathrm{Co}, \mathrm{Ni}, \mathrm{Cu}$ or $\mathrm{Zn}$ ) were widely used for biomedical applications because of their biocompatibility [2]. Magnetite has high-saturation magnetization values, whereas in general, ferrites display a moderate magnetic moment; however, cobalt ferrite in nano-sized state can exhibit saturation magnetization similar to that of magnetite [3].

For biomedical applications, SPIONs must be coated with biomaterials to improve their biocompatibility and nontoxicity, besides preventing agglomeration of MNPs in the surrounding biological media. When MNPs are introduced into the blood stream, they can interact with blood plasma proteins, resulting in aggregation and removal through the phagocytic system. Nevertheless, if hydrophobic MNPs are coated with hydrophilic polymers, interactions with plasma proteins can be prevented, resulting in increased in vivo circulation. Furthermore, surface modification of MNPs can change the magnetic properties; hence, the performance of the MNPs in biomedical applications depends on the type of coating material is used, and how these materials are linked on the magnetic core surface [4]. Natural polymers and their derivatives have been widely utilized for coating of MNPs for in vivo applications, including alginate, pullulan, dextran, mannan, starch and chitosan [5]. Magnetic nanoparticles can be prepared using polymer solutions with adequate 
precursors and hence, specific size, crystalline structure and magnetic response of these particles will depend strongly on the specific characteristics of the polymer used. Therefore, it is crucial to use well-known and well-characterized polymers to control the growth of nanoparticles, to guarantee reproducibility and to obtain the optimal conditions for development of high-crystallinity superparamagnetic nanoparticles. The afore-mentioned characteristics of the nanoparticles and its innocuity will assure its further use in specific applications, including biomedicals.

In the present study, the biopolymer agar was used because of its potential use in biomedical applications. Agar is a highmolecular-weight hydrophilic polysaccharide that occurs in the cell matrix of marine red algae (Rhodophyta), mainly from two genera: Gelidium and Gracilaria. The biological function of agar is offering a flexible structure to algae, helping them to withstand the varying forces of currents and wave motions [6,7]. Agar is extensively used as gel-forming agents, thickeners and stabilizers in the food and pharmaceutical industries because of its unique gelling properties (not found in other biopolymers), since it does not require the presence of any particular ions to form very strong gels, which are also thermo-reversible. Chemically, it is mainly composed of alternating $\beta$-(1-3)-D-galactose and $\alpha$-(1-4)-3,6-anhydroL-galactose repeating units [7]. Substitution with sulphate groups can occur at various sites in the polysaccharide chain and depends on the genus and the extraction method used [8]. Sulphate groups found in the polysaccharide chain cause kinks in the helical structure, which are responsible for the gel formation, resulting in agars with low gel strengths [9]. In general, agars from Gelidium contain much lower amount of sulphate in the molecule when compared to those from Gracilaria, and thus providing stronger gels $[7,8]$.

It is reported previously that agar can be used as a biocompatible matrix to synthesize $\mathrm{Fe}_{3} \mathrm{O}_{4}$, indicating that agar-coated MNPs may be employed in biomedical applications based on their magnetic properties. However, the physico-chemical and rheological properties of these algal polysaccharides are linked to their chemical structure and many applications are required in the formation of firm agar gels. Therefore, the possibility of obtaining chemically well-defined agar should provide grounds for in-depth investigations of structuralfunctional properties of these polysaccharides in agar-coated MNPs applications. A well-characterized agar guarantees its reproducibility and the possibility of developing magnetic nanoparticles of different compositions. Recently, our group prepared carbonyl iron particles (CIP)-agar composites with an agar extracted from the species Gelidium robustum, the main commercial agar source in Mexico [11], which showed promising results for hyperthermia therapy $[12,13]$. This species grows along the Pacific coast of Baja California and can be found in commercial stands, where it is exploited and processed for agar production.

The aim of the present study was to prepare and characterize SPIONs based on magnetite $\left(\mathrm{Fe}_{3} \mathrm{O}_{4}\right)$ and cobalt ferrite $\left(\mathrm{CoFe}_{2} \mathrm{O}_{4}\right)$ coated with a well-characterized agar extracted from G. robustum. The presence of agar coating was confirmed by Fourier transform infrared spectroscopy (FTIR) and thermogravimetric analysis (TGA). The morphology, crystal grain sizes and structure of $\mathrm{Fe}_{3} \mathrm{O}_{4}-$ and $\mathrm{CoFe}_{2} \mathrm{O}_{4}$ agars were determined by scanning electron microscope (SEM) and X-ray diffraction (XRD). Magnetic properties and in vitro cytotoxicity of agar-coated SPIONs were also reported. Based on our results, we discuss its potential uses.

\section{Experimental}

\subsection{Materials}

The agar used as polymeric coating was provided by AGARMEX (Mexico), which was originally extracted from the red algae G. robustum. The following chemicals were used for SPIONs: for the synthesis of magnetite, hexahydrated iron III chloride $\left(\mathrm{FeCl}_{3} \cdot 6 \mathrm{H}_{2} \mathrm{O}\right)$ (analytical grade, Sigma-Aldrich), tetrahydrated iron II chloride $\left(\mathrm{FeCl}_{2} \cdot 4 \mathrm{H}_{2} \mathrm{O}\right)$ (analytical grade, Sigma-Aldrich) and $\mathrm{NaOH}$ (analytical grade, SigmaAldrich); for the synthesis of cobalt ferrite, the hexahydrated cobalt II chloride $\left(\mathrm{CoCl}_{2} \cdot 6 \mathrm{H}_{2} \mathrm{O}\right)$ (analytical grade, SigmaAldrich) replaced $\mathrm{FeCl}_{2} \cdot 4 \mathrm{H}_{2} \mathrm{O}$ in the reaction. Milli-Q water was used in all the synthesis and processing steps that require water.

\subsection{Preparation of $\mathrm{CoFe}_{2} \mathrm{O}_{4}-$ and $\mathrm{Fe}_{3} \mathrm{O}_{4}$-agar nanoparticles}

Many methods were described for coating MNPs, requiring multiple processing steps and chemicals. More recently, new environmentally friendly methods were developed for in situ MNPs synthesis using algal polysaccharides $[10,14,15]$. In the present study, $\mathrm{Fe}_{3} \mathrm{O}_{4}-$ and $\mathrm{CoFe}_{2} \mathrm{O}_{4}$-agar nanoparticles were prepared at different agar concentrations $(1,2,3,4$ and 5\% w/w mass ratio) by in situ co-precipitation method according to Hsieh et al [10] with some modifications that are clearly described in this section. Agar powder from G. robustum was dissolved in distillated water and heated at $80-90^{\circ} \mathrm{C}$ for 30 min until complete dissolution. The hot agar solution was poured into a Petri dish and allowed to gel at room temperature, and after cooling, agar gels were removed from the Petri dishes and stored until use. Impregnation of the agar gels with MNPs was performed as follows: for magnetite, both $\mathrm{FeCl}_{3} \cdot 6 \mathrm{H}_{2} \mathrm{O}$ and $\mathrm{FeCl}_{2} \cdot 4 \mathrm{H}_{2} \mathrm{O}$ were mixed in a $2: 1$ proportion, and for cobalt ferrite, $\mathrm{FeCl}_{3} \cdot 6 \mathrm{H}_{2} \mathrm{O}$ and $\mathrm{CoCl}_{2} \cdot 6 \mathrm{H}_{2} \mathrm{O}$ were mixed at the same proportion $(2: 1)$. The agar gels at their corresponding concentrations were then immersed in these pre-mixed chloride solutions and aged for $12 \mathrm{~h}$. Once the time elapsed, gels were washed with deionized water to remove the chloride ions impurities, and placed in $1 \mathrm{M} \mathrm{NaOH}$ solution for $1 \mathrm{~h}$, and washed again. Then, gels were dried for $24 \mathrm{~h}$ at $60^{\circ} \mathrm{C}$ and ground into a fine powder using a spectromill ball pestle impact grinder (Chemplex, Model 1100). Finally, the MNPs-agar was sonicated for 15 min using an 
ultrasonic cleaner (Cole Parmer, 8890) and vortex for $1 \mathrm{~min}$. The supernatant containing the smallest MNPs-agar was collected and dried for characterization.

\subsection{FTIR spectroscopy}

$\mathrm{CoFe}_{2} \mathrm{O}_{4}-$ and $\mathrm{Fe}_{3} \mathrm{O}_{4}$-agar nanoparticles were characterized by FTIR Nicolet Nexus spectrometer in $\mathrm{KBr}$ medium. The spectra were scanned in the range of $500-2000 \mathrm{~cm}^{-1}$.

\subsection{SEM coupled with EDS (SEM-EDS)}

The morphology and the elemental composition of MNPs coated with agar were obtained using a SEM-energy dispersive X-ray spectroscopy (SEM-EDS) (PHILIPS XL30 ESEM scanning) and field emission scanning electron microscopy (FESEM, JEOL JSM7600F). The images were taken at 400 and $3200 \times$.

\section{$2.5 T G A$}

The thermal stability of the MNPs coated with agar was tested with TGA (Pyris1 TGA de Perkin Elmer equipment). About $5 \mathrm{mg}$ of each sample was heated from room temperature to $500^{\circ} \mathrm{C}$ at a heating rate of $10^{\circ} \mathrm{C} \mathrm{min}^{-1}$ in a nitrogen flow to obtain TGA data.

\section{$2.6 X R D$}

XRD was used to study the crystallinity and structure of MNPs coated with agar using a diffractometer (Siemens D-5000) with $\mathrm{CuK} \alpha(25 \mathrm{~mA}, 35 \mathrm{kV})$ radiation source, in a measuring range of $10-80^{\circ}$ on $2 \theta$ scale at a scan speed of $0.02^{\circ} \mathrm{s}^{-1}$. All the peaks of XRD patterns were analysed and indexed using the International Centre for Diffraction Data (ICDD) database, comparing with magnetite and ferrite standards. This technique was also used to determine the average crystal size of the coated MNPs.

\subsection{Magnetic properties}

The magnetic properties of the high-crystallinity developed magnetic nanoparticles were measured at room temperature in an alternating gradient magnetometer (AGM Micromag 2900) manufactured by Princeton Measurements.

\subsection{Cytotoxicity assay}

For the in vitro cytotoxicity assay, the cell viability of $\mathrm{Fe}_{3} \mathrm{O}_{4}$-agar was evaluated using the 3-(4,5-dimethylthiazol2-yl)-2,5-diphenyltetrazoliumbromide (MTT) assay, which was described as a very suitable method for the detection of biomaterial toxicity. The mitochondrial-dependent reduction of MTT to formazan was used to measure cell respiration as an indicator of cell viability. This analysis was performed using a glial cell line C6 from rat brain tumour. The cell line was propagated at $37^{\circ} \mathrm{C}$ in a humidified atmosphere of $5 \% \mathrm{CO}_{2}$, using Dulbecco's modified eagle medium (DMEM) with Hams F12 supplemented with $10 \%$ foetal bovine serum (FBS) and $1 \%$ antibiotics (1000 units $\mathrm{ml}^{-1}$ penicillin and $100 \mu \mathrm{g} \mathrm{ml}^{-1}$ streptomycin). Cells were incubated $\left(5 \times 10^{4}\right.$ cells $\mathrm{ml}^{-1}$ ) for $24 \mathrm{~h}$. At the end of incubation period, the agarcoated MNPs were added at different concentrations $(250,500$ and $750 \mu \mathrm{M}$ ) for another $24 \mathrm{~h}$. Optical density (OD) was measured on a Multiskan EX with stirring at $1000 \mathrm{rpm}$ for $5 \mathrm{~min}$ at a wavelength of $570 \mathrm{~nm}$ [16]. The absorbance for cells treated with culture medium alone was considered as $100 \%$ cell viability. Viability was calculated using the following equation:

$\%$ Viability $=$ OD cell treated/OD cell control.

\section{Results and discussion}

\subsection{Synthesis and characterization of agar-coated MNPs}

The FTIR spectra of $\mathrm{Fe}_{3} \mathrm{O}_{4}-$ and $\mathrm{CoFe}_{2} \mathrm{O}_{4}$-agar at different agar concentrations are shown in figure $1 \mathrm{~A}$ and $\mathrm{B}$, respectively. The spectrum of the $G$. robustum agar used was also included for comparison. The peaks in the range of $400-600 \mathrm{~cm}^{-1}$ are assigned to characteristic vibration bands of iron oxides [17], and in general, were observed in the FTIR spectra of all hybrid materials, although these bands were much more intense in $\mathrm{Fe}_{3} \mathrm{O}_{4}$-agar nanoparticles when compared to $\mathrm{CoFe}_{2} \mathrm{O}_{4}$-agar nanoparticles. $\mathrm{Fe}_{3} \mathrm{O}_{4}$-agar nanoparticles showed characteristic absorption bands around 570-600 and $440 \mathrm{~cm}^{-1}$ associated with $\mathrm{Fe}-\mathrm{O}$, and around $400 \mathrm{~cm}^{-1}$ attributed to the $\mathrm{Fe}-\mathrm{Fe}$ vibrations $[18,19] . \mathrm{CoFe}_{2} \mathrm{O}_{4}$ showed peaks around $430 \mathrm{~cm}^{-1}$ attributed to $\mathrm{Co}-\mathrm{O}$ stretching vibration modes [20,21].

The characteristics agar bands at 930 and $1070 \mathrm{~cm}^{-1}$ associated with the 3,6-anhydro-galactose bridges [22], and at $890 \mathrm{~cm}^{-1}$, attributed to the $\mathrm{C}-\mathrm{H}$ of residual carbons of $\beta$-galactose [23] were present in both $\mathrm{Fe}_{3} \mathrm{O}_{4}-$ and $\mathrm{CoFe}_{2} \mathrm{O}_{4}-$ agar nanoparticles in all agar concentrations tested. $G$. robustum agar showed a broad band at around $1650 \mathrm{~cm}^{-1}$ corresponding to the stretching vibration of the conjugated peptide bond formed by amine $(\mathrm{NH})$ and acetone $(\mathrm{CO})$ groups due to the presence of proteins [24]. The intensity of this band slightly decreased in the hybrid materials due to the presence of MNPs. It is of interest to note that these bands were more intense in the $\mathrm{Fe}_{3} \mathrm{O}_{4}$-agar nanoparticles with higher intensities at agar concentrations of $\geq 3 \%$. The absorption bands at 1370 and $1149 \mathrm{~cm}^{-1}$ due to the vibration of sulphate groups [22] were also present in all the samples. On the whole, all the FTIR spectra of agar-coated MNPs were similar to that of G. robustum agar beyond the MNPs peaks, which suggests that although MNPs were coated with agar, no chemical bonds were formed.

Thermal stability and the resulting TGA curves showing the weight loss pattern of thermal decomposition of 


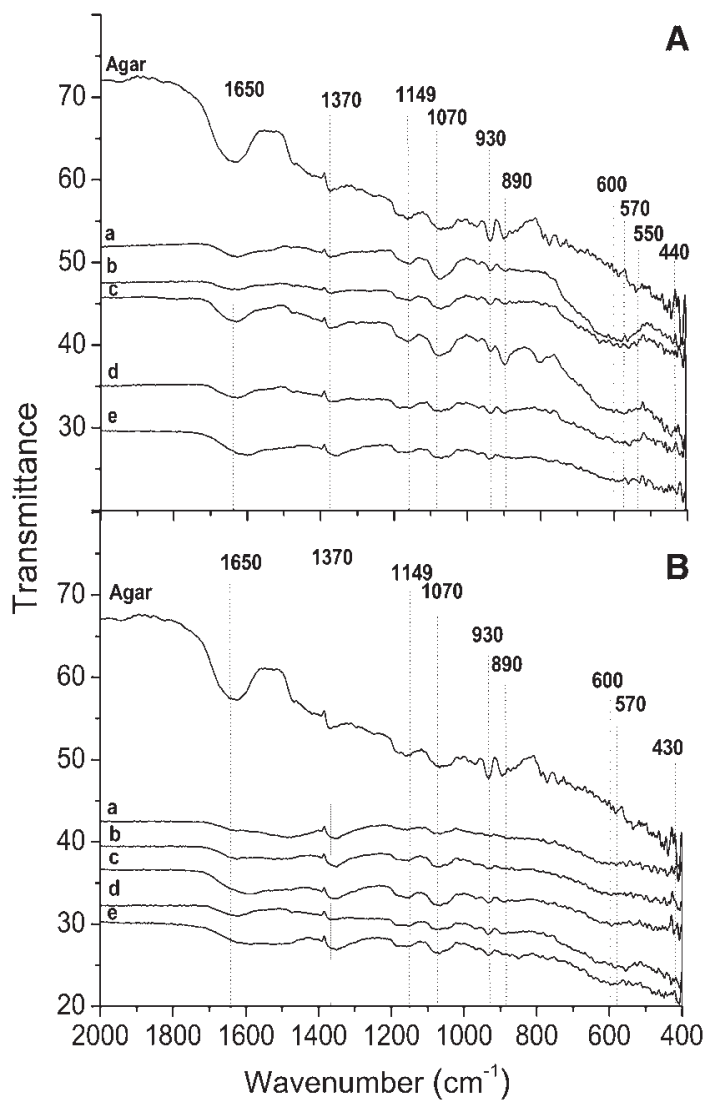

Figure 1. FTIR spectra of (A) $\mathrm{Fe}_{3} \mathrm{O}_{4}$-agar and (B) $\mathrm{CoFe}_{2} \mathrm{O}_{3}$-agar nanoparticles at 1, 2, 3, 4 and 5\% agar (a, b, c, d and e, respectively). Spectra of agar from $G$. robustum is included for comparison.

$\mathrm{Fe}_{3} \mathrm{O}_{4}$ - and $\mathrm{CoFe}_{2} \mathrm{O}_{4}$-agar nanoparticles at different agar concentrations are shown in figure $2 \mathrm{~A}$ and $\mathrm{B}$, respectively. A sample of agar from G. robustum as well as uncoated $\mathrm{Fe}_{3} \mathrm{O}_{4}$ and $\mathrm{CoFe}_{2} \mathrm{O}_{4}$ samples were also included for comparison. For agar from $G$. robustum, two stages were observed during the degradation process. The initial thermal decomposition was observed from 50 to $100^{\circ} \mathrm{C}$ with a weight loss between 10 and $12 \%$ related to release of absorbed moisture. The second step of loss of weight occurred at around $280^{\circ} \mathrm{C}$, where a major thermal decomposition attributed to thermal degradation of galactose units, release of sulphur dioxide and fragmentation of agar carbohydrates were observed, as previously described by Madera-Santana et al [25]. Then, agar showed a progressive decrease in weight, probably related to breakage of products from the second step, and finally, a complete thermal decomposition of agar occurred at around $500^{\circ} \mathrm{C}$.

For the uncoated $\mathrm{Fe}_{3} \mathrm{O}_{4}$ and $\mathrm{CoFe}_{2} \mathrm{O}_{4}$, one stage from 50 to $100^{\circ} \mathrm{C}$ was observed, which is caused by the loss of $\mathrm{OH}$ group due to the vapourization of remaining water on the surface of the material. The total weight loss of $15 \%$ for $\mathrm{Fe}_{3} \mathrm{O}_{4}$ and $36 \%$ for $\mathrm{CoFe}_{2} \mathrm{O}_{4}$ was obtained at these temperatures. In general, TGA patterns of pure agar and agar-coated MNPs

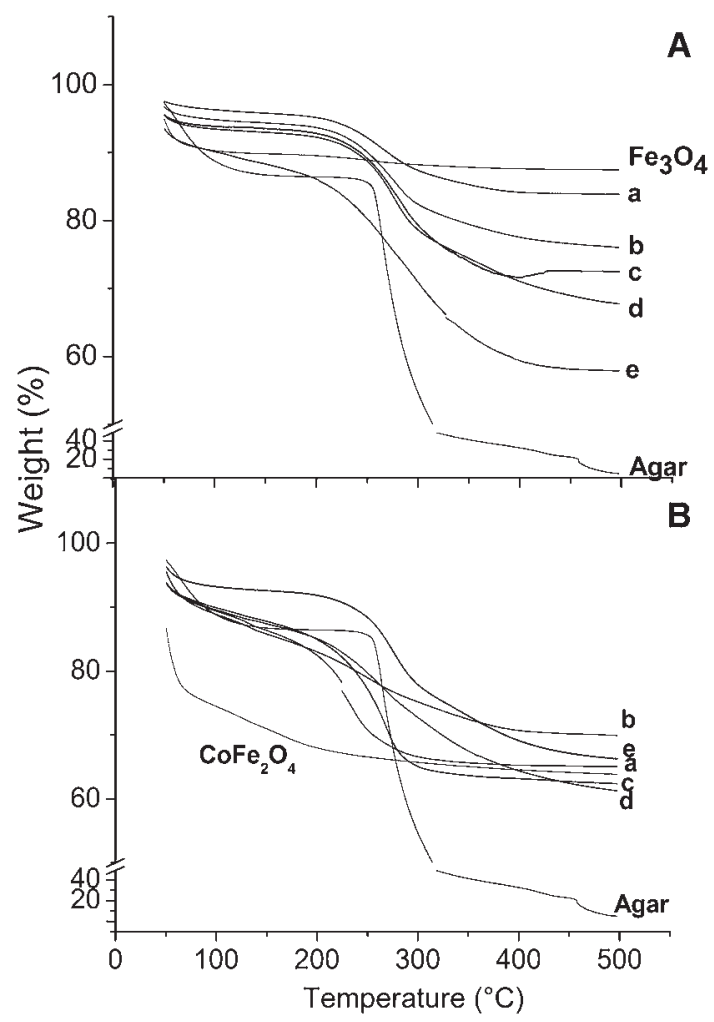

Figure 2. TGA curves of (A) $\mathrm{Fe}_{3} \mathrm{O}_{4}$-agar and (B) $\mathrm{CoFe}_{2} \mathrm{O}_{3}$-agar nanoparticles at 1, 2, 3, 4 and 5\% agar (a, b, c, d and e, respectively). Agar from $G$. robustum is included for comparison.

were similar, indicating that the weight loss of $\mathrm{Fe}_{3} \mathrm{O}_{4}$ - and $\mathrm{CoFe}_{2} \mathrm{O}_{4}$-agar are essentially provided by the agar concentration, showing a progressive decrease in weight loss with increasing concentration of agar. This pattern was more evident for $\mathrm{Fe}_{3} \mathrm{O}_{4}$-agar than for $\mathrm{CoFe}_{2} \mathrm{O}_{4}$-agar nanoparticles. At $500^{\circ} \mathrm{C}$, residuals of the agar-coated MNPs $(32 \%$ for the magnetite and $33 \%$ for the ferrite) corresponded to the metallic components.

SEM micrographs of different agar concentrations of $\mathrm{Fe}_{3} \mathrm{O}_{4}$ - and $\mathrm{CoFe}_{2} \mathrm{O}_{4}$-agar nanoparticles are shown in figures 3 and 4, respectively. These figures confirmed that all the MNPs were coated with agar. In particular, it can be observed that $\mathrm{Fe}_{3} \mathrm{O}_{4}$-agar particles at 1, 2 and 3\% agar were mostly quasi-spherical and form some agglomerates with irregular shapes (figure 3a-c), while those at 4 and 5\% agar (figure $3 \mathrm{~d}$ and e) had a higher tendency to agglomerate, probably due to the formation of inter-aggregate complexes between $\mathrm{Fe}$ ions and the polymer hydroxyl groups, promoting a physical entrapment of cations in the agar network. $\mathrm{CoFe}_{2} \mathrm{O}_{4}$ agar nanoparticles showed an undefined morphology, and also formed agglomerates at all agar concentrations (figure 4a-e). Covaliu et al [26] also described this kind of agglomerates for ferrite nanoparticles coated with sodium alginate and chitosan polymers synthesized by the co-precipitation method. 

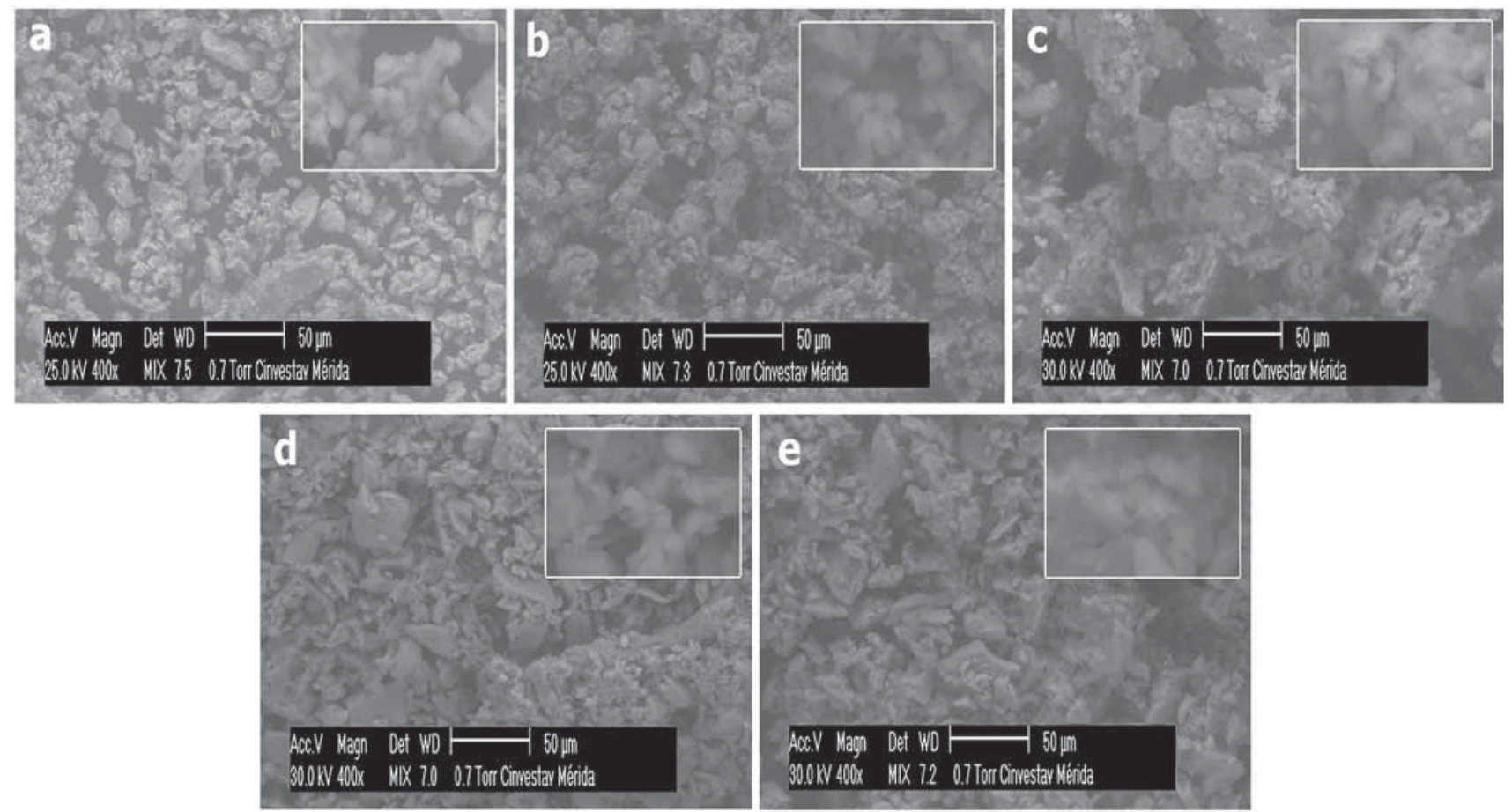

Figure 3. SEM images of $\mathrm{Fe}_{3} \mathrm{O}_{4}$-agar nanoparticles at 1, 2, 3, 4 and $5 \%$ of agar (a, b, c, d and e, respectively). Inset: images at 3200×; scale bar of $10 \mu \mathrm{m}$.
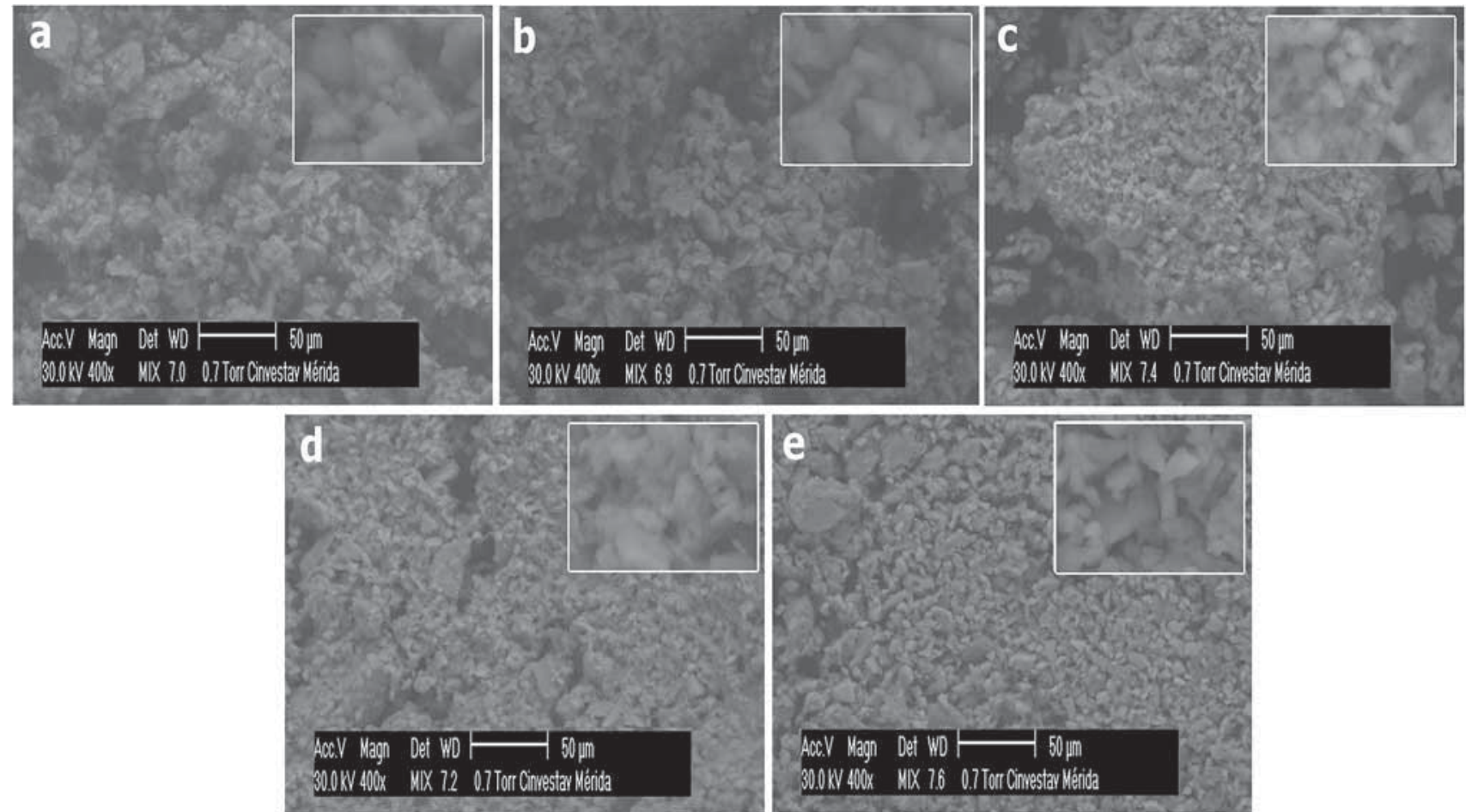

Figure 4. SEM images of $\mathrm{CoFe}_{2} \mathrm{O}_{3}$-agar nanoparticles at 1, 2, 3, 4 and 5\% of agar (a, b, c, $\mathbf{d}$ and e, respectively). Inset: images at $3200 \times$; scale bar of $10 \mu \mathrm{m}$. 
Table 1. Weight percentages of elements of $\mathrm{Fe}_{3} \mathrm{O}_{4}-$ and $\mathrm{CoFe}_{2} \mathrm{O}_{4}-$ agar coated at different agar concentrations.

\begin{tabular}{|c|c|c|c|c|c|c|c|}
\hline \multirow[b]{2}{*}{ Agar $(\%)$} & \multicolumn{3}{|c|}{$\mathrm{Fe}_{3} \mathrm{O}_{4}$-agar } & \multicolumn{4}{|c|}{$\mathrm{CoFe}_{2} \mathrm{O}_{4}$-agar } \\
\hline & $\mathrm{C}$ & $\mathrm{O}$ & $\mathrm{Fe}$ & $\mathrm{C}$ & $\mathrm{O}$ & $\mathrm{Fe}$ & $\mathrm{Co}$ \\
\hline 1 & 35.48 & 27.27 & 33.11 & 29.83 & 30.96 & 20.86 & 12.79 \\
\hline 2 & 38.36 & 28.53 & 30.06 & 16.61 & 29.8 & 30.06 & 17.9 \\
\hline 3 & 47.62 & 28.32 & 24.06 & 35.33 & 29.02 & 18.97 & 11.11 \\
\hline 4 & 31.78 & 28.14 & 40.08 & 39.75 & 32.91 & 11.42 & 6.62 \\
\hline 5 & 28.61 & 29.33 & 42.06 & 35.84 & 30.61 & 18.76 & 10.93 \\
\hline
\end{tabular}

The quantitative estimation of elements obtained directly from the spectrum through its atomic and weight percentages is shown in table 1 . The results showed the presence of $\mathrm{Fe}, \mathrm{Co}, \mathrm{O}$ and $\mathrm{C}$ in the prepared composition. In the $\mathrm{Fe}_{3} \mathrm{O}_{4}$-agar nanoparticles, a higher amount of $\mathrm{Fe}$ at the highest agar concentrations corroborated the entrapment of Fe particles in the agar gel structure. This pattern was not observed for $\mathrm{CoFe}_{2} \mathrm{O}_{4}$-agar nanoparticles.

XRD of $\mathrm{Fe}_{3} \mathrm{O}_{4}-$ and $\mathrm{CoFe}_{2} \mathrm{O}_{4}$-agar at different agar concentrations are shown in figure $5 \mathrm{~A}$ and $\mathrm{B}$, respectively. Samples of uncoated $\mathrm{Fe}_{3} \mathrm{O}_{4}$ and $\mathrm{CoFe}_{2} \mathrm{O}_{4}$ were also included for comparison. $\mathrm{Fe}_{3} \mathrm{O}_{4}$ formation was confirmed by the six characteristic peaks at $2 \theta: 30.1,35.4,43.1,53.4,57$ and $62.6^{\circ}$, which can be indexed, respectively, to the (220), (311), (400), (422), (511) and (440) planes of cubic structure of the $\mathrm{Fe}_{3} \mathrm{O}_{4}$ (JCPDS card no. 85-1436).

The XRD patterns of all $\mathrm{Fe}_{3} \mathrm{O}_{4}$-agar nanoparticles showed that the crystalline structure is preserved after the agar coating for all agar concentrations tested (figure 5A). The crystal grain sizes for $\mathrm{Fe}_{3} \mathrm{O}_{4}$-agar nanoparticles were then calculated from the Scherrer equation assuming crystals are spherical:

$$
D=\frac{0.9 \lambda}{\beta \cos \theta},
$$

where $D$ is the mean size of the ordered (crystalline) domains, $\lambda$ the wavelength of X-ray (1.54056 $\AA$ ), $\theta$ the diffraction angle in degrees and $\beta$ the width measured at half-maximum of diffracted peak (311). The crystal grain sizes were 7.8, 5.9, 6.6, 5.6 and $5.5 \mathrm{~nm}$ for the nanoparticles of magnetite coated with 1, 2, 3, 4 and $5 \%$ of agar, respectively, confirming that the prepared $\mathrm{Fe}_{3} \mathrm{O}_{4}$-agar particles are nanosized.

It is noteworthy that the smaller crystal grain sizes of $\mathrm{Fe}_{3} \mathrm{O}_{4}$-agar obtained at the highest agar concentrations showed higher tendency to form agglomerates. Similar pattern was recently described for magnetite nanoparticles of different sizes synthesized by solvothermal process [27]. These authors described the formation of spherical clusters of submicrometre sizes made of nanometre-sized primary particles, and indicated that the size of submicrometre clusters and their constituting primary clusters vary differently. They argued that as the surface energy of smaller primary

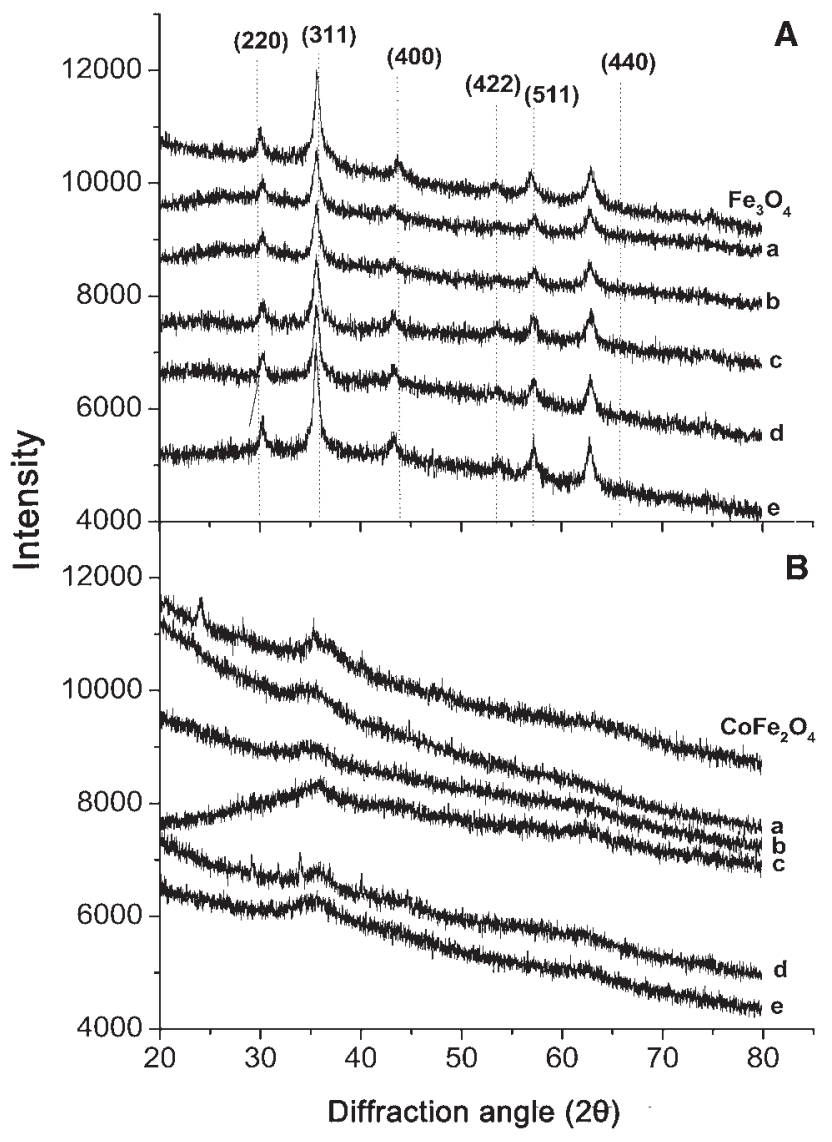

Figure 5. XRD patterns of (A) $\mathrm{Fe}_{3} \mathrm{O}_{4}$-agar and (B) $\mathrm{CoFe}_{2} \mathrm{O}_{3}$-agar nanoparticles at 1, 2, 3, 4 and 5\% agar (a, b, c, d and e, respectively). Uncoated $\mathrm{Fe}_{3} \mathrm{O}_{4}$ and $\mathrm{CoFe}_{2} \mathrm{O}_{3}$ are included for comparison.

particles is higher than the bigger ones, the probability of their agglomeration is higher and vice versa.

In contrast with magnetite, uncoated $\mathrm{CoFe}_{2} \mathrm{O}_{4}$ showed dispersed signals with no sharp diffraction patterns, suggesting an amorphous phase. In the case of $\mathrm{CoFe}_{2} \mathrm{O}_{4}$-agar nanoparticles, similar patterns were obtained at all agar concentrations maintaining the amorphous structure. The presence of a weak peak was noted at $\sim 23^{\circ}(20 \theta)$ and not a well-defined one at $35.4^{\circ}$. This could be related to the formation of the solid precursors, cobalt hydroxides $\left(\alpha-\right.$ and $\left.\beta-\mathrm{Co}(\mathrm{OH})_{2}\right)$ and akaganeite $(\beta-\mathrm{FeOOH})[28,29]$. It was reported that the co-precipitation intermediate products 


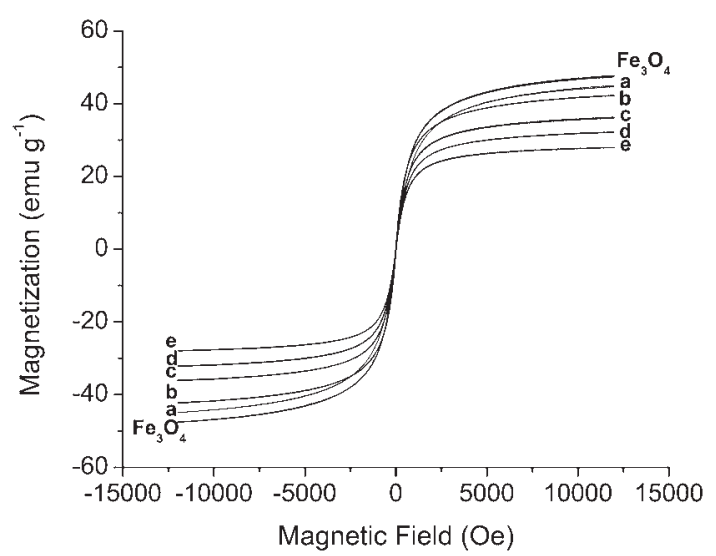

Figure 6. Magnetic curves of $\mathrm{Fe}_{3} \mathrm{O}_{4}$-agar nanoparticles at 1, 2, 3, 4 and $5 \%$ agar (a, b, c, d and e, respectively).

produce amorphous status [30]. In the same way, Matijević [31] and Cushing et al [32] reported that during the co-precipitation method, simultaneous processes like nucleation, growth, thickening and/or agglomeration may occur, and small changes in any of the variables used (i.e., temperature, $\mathrm{pH}$, salt type and concentration) can alter the nature of oxide particles. In particular, for cobalt ferrite synthesis, $\mathrm{pH}$ plays an important role on the use of $\beta-\mathrm{FeOOH}$ and cobalt hydroxides $\left(\alpha-\right.$ and $\left.\beta-\mathrm{Co}(\mathrm{OH})_{2}\right)$ as precursors before the formation of oxides $[29,33]$. The in situ co-precipitation parameters used in this study could be responsible for the synthesis of low-crystallinity $\mathrm{CoFe}_{2} \mathrm{O}_{4}$. The undefined morphology of the particles observed by SEM, instead of the expected spherical shape [34], supports the findings of Matijević [31] and Cushing et al [32]. It will be worth trying to evaluate different $\mathrm{pH}$ values by adjustments in the $\mathrm{NaOH}$ concentrations to achieve a complete synthesis of this MNP. Due to the lack of defined peaks, it was not possible to determine the particle size of $\mathrm{CoFe}_{2} \mathrm{O}_{4}$-agar particles by Scherrer formula.

Till now, the presence of agar-coated iron oxide nanoparticles was proved by FTIR, TGA and SEM analyses. XRD analysis indicated that (a) $\mathrm{Fe}_{3} \mathrm{O}_{4}$ was completely synthesized and successfully coated with agar, yielding nanosized crystals and (b) the synthesis of low-crystallinity $\mathrm{CoFe}_{2} \mathrm{O}_{4}$ was obtained by the in situ co-precipitation method used in the present study. Based on the above results, magnetic properties and cytotoxicity analysis were performed using only the $\mathrm{Fe}_{3} \mathrm{O}_{4}$-agar nanoparticles to evaluate their possible use in biomedical applications.

\subsection{Magnetic properties of agar-coated $\mathrm{Fe}_{3} \mathrm{O}_{4}$}

The magnetic properties of $\mathrm{Fe}_{3} \mathrm{O}_{4}$-agar nanoparticles at different agar concentrations are presented in figure 6. In the magnetization curves, no magnetic hysteresis loops were observed, indicating the characteristics of superparamagnetic behaviour. The saturation magnetization $\left(M_{\mathrm{s}}\right.$, maximuminduced magnetization) was 47, 42, 36, 32 and $28 \mathrm{emu} \mathrm{g}^{-1}$ for the samples prepared with 1, 2, 3, 4 and 5\% agar, respectively. For uncoated $\mathrm{Fe}_{3} \mathrm{O}_{4}$, a $M_{\mathrm{s}}$ value of $45 \mathrm{emu}$ $\mathrm{g}^{-1}$ was previously reported [35], which is similar to that obtained at the lowest agar concentrations used in this study. The saturation magnetization decreased in relation to the increase in the amount of agar molecules on the surface of the $\mathrm{Fe}_{3} \mathrm{O}_{4}$. Magnetic curves include the combined weight of both agar and $\mathrm{Fe}_{3} \mathrm{O}_{4}$, although only the $\mathrm{Fe}_{3} \mathrm{O}_{4}$ contributed to the magnetic curves. Because the weights of used $\mathrm{Fe}_{3} \mathrm{O}_{4}$ were constant, the decrease of $M_{\mathrm{s}}$ was due to the increased amount of agar added. Moreover, differences in $M_{\mathrm{s}}$ values of 4-6 emu g ${ }^{-1}$ between contiguous samples were relatively small, and can also be attributed to changes in thickness of the agar coatings. The same behaviour was reported for coated $\mathrm{Fe}_{3} \mathrm{O}_{4}$ with other biocompatible polymers like chitosan and starch [36]. In general, $M_{\mathrm{s}}$ values obtained in our study were higher $(\sim 1.7$ times $)$ than those shown in other studies using agar-coated $\mathrm{Fe}_{3} \mathrm{O}_{4}$ at 1.25, 2.5, 5 and $10 \%$ agar concentrations [10]. These differences could be probably associated with the agar gel-forming ability and solubility that rely on the relative hydrophobicity of the basic repeating unit, the alternating $\beta$-(1-3)-D-galactose and $\alpha$-(1-4)-3,6-anhydro-L-galactose, and its substitution by hydrophobic (methoxyl) and polar (sulphate, pyruvate) groups, which depends on the agar source. In this regard, no information on the physico-chemical properties of agar used by Hsieh et al [10] was provided. As mentioned before, many applications of agar require the formation of firm gels, and the possibility of obtaining chemically well-defined agars should provide grounds for in-depth investigations of structural-functional properties of these polysaccharides. Future studies should be able to correlate the physico-chemical and rheological properties of agar with molecular weight, type and location of substituent groups leading to a better understanding of agar gelation and its potential uses in the conformation of MNPs. In the present study, the agar from G. robustum had a high-molecular weight $\left(105,000 \mathrm{~g} \mathrm{~mol}^{-1}\right)$, low sulphate content $(<1 \%)$ and, thus, high gelling power $\left(\sim 1000 \mathrm{~g} \mathrm{~cm}^{-1}\right)$, which render suitable properties for specific applications to our investigation $[37,38]$.

Coercivity (defined as the magnetic field required to bring the magnetization back to zero) was 10.1, 11.1, 9.9, 8.6 and 3.3 Oe for $\mathrm{Fe}_{3} \mathrm{O}_{4}$ particles coated with 1, 2, 3, 4 and 5\% of agar, respectively, confirming their superparamagnetic behaviours [39]. Smaller coercivities were observed at the highest concentrations of agar, which are attributable to thicker surface agar coatings. Larumbe et al [40] also observed such decrease in coercivity for coated $\mathrm{Fe}_{3} \mathrm{O}_{4}$ nanoparticles. They evaluated the effect of $\mathrm{SiO}_{2}$ coating on $\mathrm{Fe}_{3} \mathrm{O}_{4}$ MNPs and found a reduced $M_{\mathrm{S}}$ and lower coercivity as compared to analogous uncoated $\mathrm{Fe}_{3} \mathrm{O}_{4}$ nanoparticles. These authors attributed this decrease to the influence of the dipole interactions between particles, which promotes surface spin-disorder by the presence of a coat bonded to the MNP surface, leading to a reduction in magnetization. It was also described that coercivity decreases in relation to a reduction in crystal size 


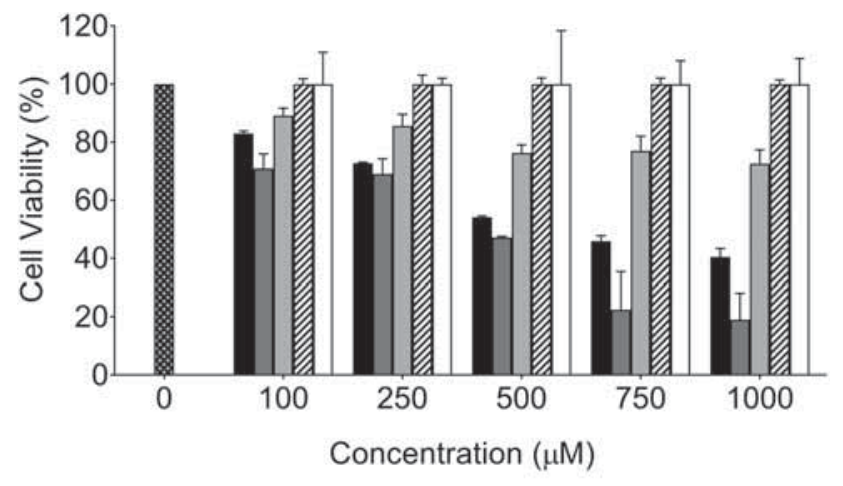

网 $0 \%$

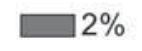

$3 \%$

$4 \%$ $5 \%$

Figure 7. Cell viability after $24 \mathrm{~h}$ exposure to $100,250,500,750$ and $1000 \mu \mathrm{M}$ of $\mathrm{Fe}_{3} \mathrm{O}_{4}$-agar nanoparticles at 1, 2, 3, 4 and 5\% agar. The control is shown as untreated cells. Results were normalized in relation to control.

[26,41], which is corroborated with our findings. Crystal sizes $<8 \mathrm{~nm}$ obtained, and superparamagnetic behaviour at room temperature also indicates a single domain in $\mathrm{Fe}_{3} \mathrm{O}_{4}-$ agar nanoparticles. Ferrimagnetic materials smaller than a critical size $(<15 \mathrm{~nm}$ in diameter) are called single-domain particles [42]. The single-domain particles are related with superparamagnetism since all the spins are aligned in the same direction and therefore, the particle is uniformly magnetized, which is an advantage for magnetic hyperthermia applications, allowing the heating to be restricted to the tumour area $[39,43]$. Moreover, it was reported that MNPs with a size around 8-24 nm will be useful for in situ hyperthermia treatment of cancers using an alternating current magnetic field [44].

\subsection{In vitro cytotoxicity study of agar-coated $\mathrm{Fe}_{3} \mathrm{O}_{4}$}

The cell viability from the MTT assay was determined to evaluate the potential biocompatibility of the $\mathrm{Fe}_{3} \mathrm{O}_{4}$-agar nanoparticles. Cell viability after exposure to $\mathrm{Fe}_{3} \mathrm{O}_{4}$-agar nanoparticles of concentrations 100, 250, 500, 750 and $1000 \mu \mathrm{M}$ at their corresponding agar concentrations (1, 2, 3,4 and $5 \%$ ) is shown in figure 7 . It can be observed that $\mathrm{Fe}_{3} \mathrm{O}_{4}$ coated with $\geq 3 \%$ agar exposed at all doses tested is not cytotoxic. Moreover, materials with cell viability $\geq 80 \%$ were recognized as biocompatible [2]. At low concentrations of agar (1 and 2\%), MNPs showed low toxicity and exhibited a dose-dependent effect, increases cytotoxicity as $\mathrm{Fe}_{3} \mathrm{O}_{4}$-agar concentration increases. Similar results were obtained in cell viability by the MTT assay for neat SPIONs at the same doses [45]. These authors evidenced that MNPs induced oxidative stress and subsequent apoptosis by their inherent toxicity. It was also demonstrated that exposure to iron nanoparticles induces reactive oxygen species (ROS) production and causes oxidative stress, which is linked to DNA damage, mutations and cancer [46,47]. In general, nanoparticles coated with biopolymers have lower toxicity due to the presence of biocompatible coating, which limits adsorption sites for proteins, ions and other components, and also due to changes in particle characteristics (i.e., size, charge and hydrophobicity) that can significantly affect the affinity of proteins to the surface of such nanoparticles [3]. The lack of cytoxicity found for $\mathrm{Fe}_{3} \mathrm{O}_{4}$ coated at agar $\geq 3 \%$ could indicate optimal surface characteristics, which could contribute to its biocompatibility. However, despite our promising results, further studies and additional toxicological evaluations should be performed. Complementary in vitro bioassays will define its suitable application of these MNPs in the biomedical field.

\section{Conclusions}

In this study, nanocomposites containing iron oxide nanoparticles, $\mathrm{Fe}_{3} \mathrm{O}_{4}$ or $\mathrm{CoFe}_{2} \mathrm{O}_{4}$, coated with a well-characterized agar extracted from the red algae, G. robustum were prepared using a simple in situ co-precipitation method. The results showed that superparamagnetic nanoparticles of $\mathrm{Fe}_{3} \mathrm{O}_{4}$ coated with 1, 2, 3, 4 and 5\% of agar (with crystal grain sizes $<8 \mathrm{~nm}$ ) can be successfully prepared using this method. In contrast, under the same experimental conditions, using the same co-precipitation method with the adequate precursor, low-crystallinity $\mathrm{CoFe}_{2} \mathrm{O}_{4}$-agar nanoparticles were obtained, indicating the decisive role of the agar-specific properties during particles' preparation/formation. Besides the nanosized particles obtained, $\mathrm{Fe}_{3} \mathrm{O}_{4}$-agar at all agar concentrations showed a single domain particle with superparamagnetic behaviour at room temperature, showing high saturation magnetization values. In addition, $\mathrm{Fe}_{3} \mathrm{O}_{4}$-agar nanoparticles with low agar concentrations ( 1 and $2 \%$ ) showed reduced toxicity at 100 and $250 \mu \mathrm{M}$ particle concentrations, while those coated with $\geq 3 \%$ agar tested at all the doses were non-cytotoxic. All these results could indicate that $\mathrm{Fe}_{3} \mathrm{O}_{4}$ coated with agar from G. robustum at 3,4 and 5\% can be considered as promising candidates for biomedical applications, specially, for hyperthermia treatments. A broader study of the in situ coprecipitation parameters used for these agar solutions needs to be developed; in particular, $\mathrm{pH}$ should be studied in depth to enhance the crystallinity and size of the cobalt ferrite nanoparticles.

\section{Acknowledgements}

The first author acknowledges CINVESTAV and CONACYT (375342) for the scholarship support to carry out this research work. We want to express our acknowledgment to C Chávez Quintal for her technical support, and to A R Cristobal Ramos for her valuable help in obtaining SEM images.

\section{References}

[1] Bañobre-López M, Teijeiro A and Rivas J 2013 Rep. Pract. Oncol. Radiother. 18397

[2] Mahmoudi M, Simchi A, Milani A S and Stroeve P $2009 \mathrm{~J}$. Colloid Interf. Sci. 336510 
[3] Mahmoudi M, Sant S, Wang B, Laurent S and Senet T 2011 Adv. Drug Deliv. Rev. 6324

[4] Karimi Z, Karimi L and Shokrollahi H 2013 Mat. Sci. Eng. C 332465

[5] Uthaman S, Joon Lee S J, Cherukula K, Cho C S and Park I P 2015 Biomed. Res. Int. 2015959175

[6] Craigie J S 1990 Biology of the red algae (Cambridge: Cambridge University Press) p 221

[7] Armisen R and Galatas F 2000 Handbook of hydrocolloids (Boca Raton: CRC Press) p 21

[8] Murano E 1995 J. Appl. Phycol. 7245

[9] Lahaye M and Rochas C 1991 Hydrobiologia 221137

[10] Hsieh S, Huang B Y, Hsieh S L, Wu C C, Wu C H, Lin P Y et al 2010 Nanotechnology 21445601

[11] Robledo D 2005 Seaweed resources of the world (Japan: Japan International Cooperation Agency-JICA) p 331

[12] Díaz-Bleis D, Freile-Pelegrín Y, Vales-Pinzón C, MartínezTorres P and Alvarado-Gil J J 2012 Int. J. Thermophys. 33 2125

[13] Díaz-Bleis D, Freile-Pelegrín Y, Vales-Pinzón C and AlvaradoGil J J 2014 Carbohydr. Polym. 9984

[14] Nath D and Banerjee P 2013 Environ. Toxicol. Pharmacol. 36 997

[15] Mahdavinia G R, Baghban A, Zorofi S and Massoudi A 2014 J. Mater. Environ. Sci. 5330

[16] Mosmann T 1983 J. Immunol. Methods 6555

[17] Gillot B 1994 Vib. Spectrosc. 6127

[18] Ma H, Qi X, Maitani Y and Nagai T 2007 Int. J. Pharm. 333 177

[19] Andrade A L, Souza D M, Pereira M C, Fabris J D and Domingues R Z 2009 Cerâmica 55420

[20] Jacintho G V M, Brolo A G, Corio P, Suarez P A Z and Rubim J C J 2009 J. Phys. Chem. C 1137684

[21] Pui A, Gherca D and Carja G 2001 J. Nanomater. 6 1783

[22] Pereira L, Amado A M, Critchley A T, van de Velde F and Ribeiro-Claro P J A 2009 Food Hydrocoll. 231903

[23] Matsuhiro B 1996 Hydrobiologia 326-327 481

[24] Cristiaen D and Bodard M 1983 Bot. Mar. 26425

[25] Madera-Santana T J, Misra M, Drzal L T, Robledo D and FreilePelegrín Y 2009 Polym. Eng. Sci. 491117

[26] Covaliu C I, Berger D, Matei C, Diamandescu L, Vasile E, Cristea C et al 2011 Nanopart. Res. 136169
[27] Uribe Madrid S I, Pal U and Sánchez-De Jesús F 2014 Adv. Nano Res. 2187

[28] Sugimoto T 2000 Fine particles, synthesis, characterization and mechanism of growth; Surfactan Science Series 92 (New York: Marcel Dekker) p 58

[29] Cui H, Zhao Y, Ren W, Wang M and Liu Y J 2013 J. Alloys Compd. 56233

[30] Meng Y Y, Liu Z W, Dai H C, Yu H Y, Zeng D C, Shukla S et al 2012 Powder Technol. 229270

[31] Matijevićn E J 1977 Colloid Interf. Sci. 58374

[32] Cushing B L, Kolesnichenko V L and Connor C J O 2004 Chem. Rev. 1043893

[33] Cao X and Gu L 2005 Nanotechnology 16180

[34] Joshi M H, Lin Y P, Aslam M, Prasad P V, SchultzSikma E A, Edelman R et al 2009 J. Phys. Chem. C 113 17761

[35] Zhao F, Zhang B and Feng L 2012 Mater. Lett. 68112

[36] Kim D H, Lee S H, Im K H, Kim K N, Kim K M, Shim I B et al 2006 Curr. Appl. Phys. 6S1 242.

[37] Freile-Pelegrín Y, Robledo D and Serviere-Zaragoza E 1999 Hydrobiologia 398/399 501

[38] Freile-Pelegrín Y, Madera-Santana T J, Robledo D, Veleva L, Quintana P and Azamar J A 2007 Polym. Degrad. Stab. 92 244

[39] Issa B, Obaidat I M, Albiss B A and Haik Y 2013 Int. J. Mol. Sci. 1421266

[40] Larumbe S, Gomez-Polo C, Perez-Landazabal J and Pastor J M 2012 J. Phys. Condens. Matter 241

[41] Kolhatkar A G, Jamison A C, Litvinov D, Willson R C and Lee T R 2013 Int. J. Mol. Sci. 1415977

[42] Chatterjee J, Haik Y and Chen C-J J 2003 J. Magn. Magn. Mater. 257113

[43] Tartaj P, Del Puerto Morales M, Veintemillas-Verdaguer S, Gonzalez-Carreño T and Serna C J 2003 J. Phys. D: Appl. Phys. 36 R182

[44] Li Z, Kawashita M, Araki N, Mitsumori M, Hiraoka M and Doi M 2010 Mat. Sci. Eng. C 30990

[45] Naqvi S, Samim M, Abdin M, Ahmed F J, Maitra A, Prashant C et al 2010 Int. J. Nanomed. 5983

[46] Karlsson H L, Cronholm P, Gustafsson J and Möller L 2008 Chem. Res. Toxicol. 211726

[47] Apopa P L, Qian Y, Shao R, Guo N L, Schwegler-Berry D, Pacurari M et al 2009 Part. Fibre Toxicol. 61 